\title{
Exploring Resilience: in the Face of Trauma
}

\author{
Shana Hormann ${ }^{1}$ (D)
}

Received: 12 February 2018 / Accepted: 22 May 2018 / Published online: 1 June 2018

(C) Springer International Publishing AG, part of Springer Nature 2018

\begin{abstract}
What exactly is that quality of resilience that carries people, organizations, and communities through traumatic times? As a construct, resilience is built on the underlying assumption that an individual or organization has undergone a situation of 'significant adversity' and has adapted positively, returning to or increasing in performance and psychological wellbeing (Riolli and Savicki Omega, 31(3): 227-233, 2003; Sutcliffe and Vogus 2003). Definitions of resilience range on a continuum from survival to adaptation to competence to healing to hardiness to robustness to wellness (Werner American Psychological Society 81-85, 1995; Masten and Coatsworth American Psychologist, 53(2): 205-220, 1998; Luthar et al. Child Development, 71(3): 573-575, 2000; Coutu Harvard Business Review, 80(5): 46-52, 2002; Maddi 2002). Resilience is an important quality for leaders who are committed to the health of organizations. Organizational health is negatively impacted by organizational trauma; parallel to individuals' experiences, group and organizational cultures and dynamics are wounded by trauma. While leaders cannot always protect organizations from trauma, leaders can strengthen resilience, recognize when trauma occurs, address the trauma effectively, and protect the system from spiraling into traumatization (Vivian and Hormann O.D. Practitioner, 34(4): 52-57, 2002). This paper offers recommendations for addressing organizational trauma as well as strengthening resilience, individually and collectively. Stories are shared from several organizations, demonstrating the importance of leadership and resilience in the face of trauma.
\end{abstract}

Keywords Organizational trauma $\cdot$ Resilience $\cdot$ Trauma $\cdot$ Organizational strengths

\section{Introduction}

\section{What Exactly Is that Quality of Resilience that Carries People through Life?}

Psychologist Norman Garmezy began asking this question over 40 years ago with regard to children of schizophrenic parents. While many children that he studied suffered psychological

Shana Hormann

shormann@antioch.edu

1 Antioch University Seattle, 2400 3rd Street, Suite 200, Seattle, WA 98121, USA 
illness as a result of growing up with mentally ill caregivers, others did not. Garmezy concluded that the healthier youth had resilience, a quality that supported and promoted mental health (Haggerty et al. 1994). Subsequent research on high-risk children indicate that young children with good coping abilities demonstrate the ability to elicit positive responses from caregivers, especially under adverse conditions (Werner 1995). As these children grow they find at least one competent and emotionally stable adult with whom to bond, and they increase their ability "to appraise stressful life events correctly" (Werner 1995, p. 82). These children know the importance of ongoing connection to others, remain vigilant about what is happening around them, and are astute at reading their environments.

Resilient individuals of all ages build and rely on strengths, on social, emotional, and physical resources. Social work practitioners use a strengths perspective with clients. Instead of focusing on problems, i.e., "What's wrong with this person?" social workers ask, "What are the strengths that helped this person survive?" (Bell 2003) The strengths perspective assumes that people are resilient and have the capacity to increase their resilience.

Resilience is an important quality for social workers, psychologists, for all who work with trauma survivors. Trauma work creates susceptibility to compassion fatigue and secondary traumatic stress (Bride et al. 2007; Figley 1995; Stamm 1999). Practitioners have to be aware of these risks and take steps to be healthy themselves in order to be effective responders in times of crisis or when assisting others with their trauma recovery. Finally, resilience is an important quality for organizations and for managers committed to the health of organizations and the members. Organizational health is negatively impacted by organizational trauma, trauma that may become embedded in the workplace.

My interest is in uncovering characteristics of resilience that allow systems to withstand trauma, and that contribute to the building of resilience in individuals and organizations following a trauma. This paper reviews definitions and characteristics of resilience and offers recommendations for individuals and organizations that are interested in building and strengthening resilience, individually and collectively.

\section{Definitions}

The term resilience comes from Latin and means to spring or jump, to be buoyant, to bounce back (Steinmetz et al. 1998). As a construct, resilience is built on the underlying assumption that the individual or organization has undergone a situation of 'significant adversity' and has adapted positively, quickly returns to or increases in performance and psychological wellbeing (Riolli and Savicki 2003). 'Significant adversity' is defined in the resilience literature as being a significant threat, e.g. a trauma. Resilient systems have the capacity to recover structure and function after disturbance, to bounce back. A highly resilient community or system may be completely disrupted by disturbance but quickly returns to a balance among the elements. These self-righting tendencies are evident in all living systems (Cicchetti et al. 1993; Werner 1995).

Nature is a wonderful teacher about resilience. She teaches us that the greatest resilience and resistance to trauma is where there is the greatest diversity (Kate Davies, personal correspondence, February 8, 2005). The resilience literature draws from natural systems and applies learnings from them to social systems, to individuals and organizations. The following story is an example of a natural system impacted by a social system. 
In 1989 more than 10 million gallons of slick shiny black oil oozed from the Exxon Valdez and covered beach, rocks, birds, and mammals in Prince William Sound. There was a wide range of responses to the catastrophe. One response was to witness the magnitude of the impact, the loss of life, and act to help the natural and social systems. People volunteered time with the rescue teams or sent financial donations for the clean up efforts and to support the families whose livelihoods were wiped out by the spill. A second response was to deny the size of the impact and to calculate the clean-up in dollars, the cost to the company. After three years Exxon claimed that the area was in a good state of recovery. This was blatantly untrue. Of the 28 species initially listed as severely impacted, only bald eagles and river otters had officially "recovered". Residual oil could still be found on beaches - ten years after the spill (Okey 2000). Large volumes of oil penetrated so deeply into the earth that substantial quantities continue to leach out today.

From the Prince William Sound perspective, a natural system was assaulted by a human-made disaster. The natural world is not designed to withstand such a violation. Contrast this with the onslaught in the Everglades caused by Hurricane Andrew, an example of a natural system damaged (and in some ways destroyed) by another natural system. The natural system of the Everglades came back healthier than it was before; within 20 days surviving trees and shrubs had sprouted new growth (Alper, 1992).

The oil that continues to leach out in Prince William Sound is like the grief that we hold inside. Taking on someone else's grief or working in an environment where we are continuously exposed to trauma, is parallel to Prince William Sound taking on oil. What are the keys to resiliency in a natural system that is able to transform or reconfigure itself, such as the Everglades? Do systems, social or natural, have the option of returning to the former state after a trauma?

There are a growing number of voices calling for a definition of resilience that is beyond self-righting tendencies, beyond survival. These voices are working to create a definition that reflects individual and organizational hardiness (Maddi 2002). For example, the management and information systems field examines systems that respond to disruption and trauma without engaging in regressive behaviors for long periods of time (Horne and Orr 1998). Social work research examines strategies and resources that allows clients and practitioners to be well, enthusiastic, and energetic (Bell 2003). Additionally, there is writing that focuses specifically on healing and hope (Maddi 2002; Wolin and Wolin 1994).

Current definitions of resilience range on a continuum from survival to adaptation to competence to healing to hardiness to robustness to wellness (Coutu 2002; Luthar et al. 2000; Maddi 2002; Masten and Coatsworth 1998; Werner 1995). Increasingly resilience equals wellness, not merely an absence of dysfunction or evidence of the capacity to survive. Focusing on wellness allows for building on existing individual and organizational capacity, on health and strengths, rather than focusing on solving problems, on illness and weaknesses.

Diane Coutu in her article How Resilience Works (2002) reviews the resilience literature and provides the simple yet elegant definition that resilience is the skill and the capacity to be robust under conditions of enormous stress and change. Coutu identifies that the characteristics of resilience identified in the literature can be grouped into three distinct areas:

- Facing down reality

- Search for meaning

- Ritualized ingenuity

The first, facing down reality, is acceptance of people, places and things as they are in this moment. The second, the search for meaning, is an individual and collective journey into values and beliefs. Finally, ritualized ingenuity is an uncanny ability to improvise within established practices and procedures. 


\section{Organizational Trauma}

In a manner parallel to individuals' experiences, group and organizational cultures and dynamics are impacted by trauma. For example, the effects of trauma influence an organization's identity and worldview in the same way that an individual is influenced by her/his trauma experience (Hormann and Vivian 2005). The impacts of trauma are often greater if superimposed on individuals or groups who are of high-risk status (Masten and Coatsworth 1998).

Howard Stein (personal communication, September 28, 2004), a psychological anthropologist, shared this definition of organizational trauma:

Groups, for example workplace organizations, can experience traumas just as individuals and families can. We speak of September 11, 2001 as a "national trauma," not just metaphorically, but literally. The protective emotional membrane was penetrated, violated, perhaps destroyed. At any level, trauma is an experience for which a personfamily-group is emotionally (not only cognitively) unprepared, an experience that overwhelms ones' defensive (self-protective) structure and leaves one feeling totally vulnerable, at least temporarily helpless.

What conditions are necessary for organizational trauma to occur? According to Geoff Bellman, consultant, two conditions must be present: First, an organization has to exist as a body. In other words, its members are bound in relationships and in communities by covenants, beliefs, and values. For trauma to be experienced in an organization, individuals must recognize themselves as in community, as members of relationships that are important to them. It is not enough that people simply show up to work at the same place. Second, the organism, the organization, has to experience a body blow-or something that is felt as a blow (G. Bellman, personal communication, July 26, 2004). The trauma may be direct or indirect. As my colleague Pat Vivian and I discovered,

"Sometimes trauma is direct as in the bombing of a women's health clinic that provides abortions. Often trauma is indirect, the result of an organization's continual exposure to trauma through the very nature of its work. Domestic violence service agencies and emergency response organizations are examples of organizations susceptible to indirect trauma" (Hormann and Vivian 2005, p. 3).

Trauma is experienced across a wide range of organizations. For example, law enforcement agencies provide emergency response and are, therefore, susceptible to indirect trauma. Losing an officer in the line of duty is a source of direct trauma (Violanti and Gehrke 2004).

Moving from trauma to resilience requires the three characteristics identified by Coutu (Coutu 2002): facing down reality, search for meaning, and ritualized ingenuity. I will look at each of these three characteristics in turn.

\section{Characteristics of Resilience}

\section{Facing Down Reality}

Facing down reality refers to the ability to truly understand and accept the reality of a situation. An ability to see possibilities, to dream big dreams, and to be optimistic can be positive traits for individuals and organizations. However, when survival is at stake, possibilities and 
optimism need to be firmly connected to probabilities, to day-to-day reality. Resilient people and organizations are clear about what is needed for survival, a lesson that humans apparently learn at a young age. As mentioned earlier (p. 2), high-risk youth who thrive despite living in adverse and even abusive conditions engage in relationship with at least one emotionally stable adult and pay attention to life events around them (Werner 1995). They know that connection with others and paying attention to changes in their environment can mean the difference between life and death. According to Bellman and Ryan (Bellman and Ryan 2009), "We are wired to survive; understanding our Reality is essential to that. As a species, our advancement has depended on being alert to the world around us" (p. 43).

Facing reality can be difficult and unpleasant, and at times very painful. The inability or unwillingness to face pain leads many people to succumb to the temptation to cope through denial (Coutu 2002). Those in denial act as though there are no problems and permit no evidence to the contrary. Therefore, undiscussables and secrets abound as individuals distort truths or act as if what is untrue is true (Hammond and Mayfield 2004; Senge 1999). Dishonesty and secrets create environments that are more likely to be traumatized and less resilient, as information will not be available when it is needed.

The addiction model can be applied to organizations when denial is prevalent throughout the system (Schaef and Fassel 1988). Addiction is a process or substance that has negative impact and over which the addict, person, or social system is powerless. Addiction "begins to have control over us in such a way that we feel we must be dishonest with ourselves or others about it" (Schaef and Fassel 1988, p. 57). Denial and addiction are the antitheses of facing reality.

In the introduction to Trauma and recovery: The aftermath of violence-from domestic abuse to political terror author Herman (Herman 1992) states, "The ordinary response to atrocities is to banish them from consciousness. Certain violations of the social compact are too terrible to utter aloud: this is the meaning of the word unspeakable" (p. 1). Facing reality may mean facing the unspeakable, such as individual terror. Facing reality may also mean facing the undiscussable, such as trauma embedded in the organizational culture.

My colleague, Pat Vivian, and I help leaders and members of non-profit organizations and government agencies face reality and explore their organizational dynamics using our Strengths and Shadows model, a model that depicts the organizational system (Vivian and Hormann 2002). Strengths indicate the strongest qualities present (Seligman and Csikszentmihalyi 2000), a system's positive capabilities (Luthans and Avolio 2003). In the Strengths and Shadows model "Strengths" also refer to values and assumptions that support an organization's successful accomplishment of its mission. We use the term "Shadow" for elements that are denied, rejected, hidden, and undiscussable. Shadow elements frequently hinder either accomplishment of the mission or the organization's sustainability. Strengths can be overly relied on or rigidly and/or inappropriately applied, resulting in Shadow elements. For example, when an organizational Strength is a shared value for autonomy, Shadow behaviors may include organizational members becoming isolated and resultant work being disjointed. Lack of responsibility may also be a Shadow as individuals and teams may perceive themselves as accountable only to "their" work and not to coordinating with others or to meeting deadlines other than those they set. When existing Strengths are overly relied on, additional qualities or Strengths that might be useful to the organization are not developed (Vivian and Hormann 2002). Engaging in the exercise of identifying organizational Strengths and Shadows helps all involved to "see" the culture, to view the values and dynamics as systemic rather than 
interpersonal in nature. Facing down reality includes shining light on the Shadows and engaging with the hope held within the Strengths (Appendix 1).

\section{The Search for Meaning}

Meaning making helps individuals to build bridges from present experiences to futures of hope; constructing meaning builds resilience and is an act of resilience. According to Coutu (Coutu 2002) "Resilient people devise constructs about their suffering to create some sort of meaning for themselves and others" (p. 48).

When an organization identifies that it is traumatized and suffering, the leaders and members may build or strengthen resilience by rediscovering meaning. Coming together to discover meaning confirms and makes explicit their shared connection to organizational values and beliefs. Coutu (Coutu 2002) writes, "Since finding meaning in one's environment is such an important aspect of resilience, it should come as no surprise that the most successful organizations and people possess strong value systems. Strong values infuse an environment with meaning because they offer ways to interpret and shape events" (Coutu 2002, p. 49). Employees need to have a shared understanding of the organizational reality so their decisions and actions are aligned with the mission and goals. Meaning making that is done in isolation may result in fragmentation of the organizational culture and employees working at cross purposes with one another, lowering resilience (Appendix 2).

Making meaning together addresses the fact that disconnection and isolation diminish individual and organizational resistance to illness or hardiness, increasing vulnerability to the impact of traumatic events. Resilience increases dramatically when individuals and groups are able to take purposeful action with others, and stay connected (Herman 1992).

Another way to find meaning is for people to take care of one another. When individuals begin to feel hopeless or helpless, others can remind them of hope and provide inspiration (Maddi 2002). Palmer (1990) writes, "The insight of our spiritual traditions is not to deny the reality of the outer world, but to help us understand that we create the world, in part, by projecting our spirit on it-for better or worse" (p. 6). The reality of the outer world includes trauma but it also includes healing, resilience, and hope.

Why do so many choose a life of service that involves working with trauma? One question asked a sampling of staff and volunteers who worked at Seattle Rape Relief from 1972 to 1998 was, What did you like best about working with Rape Relief? (Hormann and Vivian 2004) A wide range of answers from over 40 interviews were clustered into three categories:

- Privilege to work with survivors, be of service, service delivery

- Very important social justice work, commitment to social change

- Being part of a community, friendships, support

Respondents generally gave more than one answer, combining direct service and/or social change work with support from friends who were co-workers or volunteers. The research supports our finding that service providers are often restored by responding to others' suffering, by being of service (Wolin and Wolin 1994). Evidently projecting a spirit of caring, healing, and empathy heals not only the identified wounded, but the healer as well. Seattle Rape Relief was a resilient organization for over 20 years. The agency's death was in large part the result of unresolved trauma. Members lost sight of what held meaning and so lost the very elements that provided resilience: service, social justice, community. In short, they lost heart. 
As a faculty member at Antioch University Seattle I had opportunities to introduce the topic of resilience and explore with students ways to increase their individual wellness as well as wellness within their organizations. The following email exchange between me and an advisee in the graduate Organizational Psychology program illustrates meaning making through interpersonal interactions. The exchange is about facing reality and resilience. In addition to increasing individual resilience, organizational resilience is increased through strengthening connections, sharing information, and the development of community/collective responses (Horne and Orr 1998) (Appendix 3).

This is an email exchange between me and an Organizational Psychology student. J. was a Chief Park Ranger, National Park Service (NPS), stationed at Mt. Rainier National Park. My comments are in italics.

$\mathrm{J}$, senior park ranger, writes:

Yesterday was a "run from the building" day.... Here is the string...

Thursday...noon to 2: conversation with the sister of a 23 year old climbing ranger who was killed on a rescue 10 years ago August. Dialogue about line of duty deaths, her family's struggle, frustrations with the NPS, what has changed in the last 10 years as a result of the deaths (two rangers died on a rescue when a crampon failed and they both slid $1000 \mathrm{ft}$ to their deaths); what have I as a Chief Ranger done to make sure it doesn't happen again. We talked about how can the NPS expect 21 and 23 year olds to make the kind of decisions that we want them to make in life and death situations.

Thursday...8 p.m.: vehicular fatality on 410 . Second year ranger, 26 years old, she is first on scene to a car vs. tree. The tree won and the passenger is cut in two. Driver is having a heart attack.

Friday... 7 a.m.: rescue for a firefighter who is climbing the mountain...turns into a recovery at 8:30 as we finally see that CPR is in progress. 26 year old ranger has to pull his climbing partner off of him on 50 degree slope. The partner has been doing CPR for over $2 \mathrm{~h}$; and we still had to get him off the chute because the sun was now up and the rocks were starting to rock and roll

Friday 9: death notification to a father; who in turn would tell a 29 year old widow with 3 and 6 year old children Friday 9:20: death notification to a fire chief; professional condolences

Friday 3-ish: meet the climbing ranger who was on scene during the morning. Defusing with him one-on-one.

Friday 3:30: climbing partner interview; connect him by phone with father of the man who died so he can relay what happened

Friday 5:00: I can finally leave to go home...

A sense of wanting to run away from it all. I wasn't feeling too resilient today...my staff seems to be much more resilient than I... a good thing since they are picking the bodies up off the mountain. Thanks for listening...

Hi J.

When I first wake up in the morning I check in with myself and with the Holy Mother (Insert your own Source or Higher Power here... Why do we think the Creator cares how we refer to her?). This morning I went to this deep place and connected with grief. I don't think we have any choice about grief--death and loss cause grief. Our grief honors our heart connection to those we love. You spoke to resilience. I've come to respect that resilience is about accepting life as it presents itself and seeing creative options at the same time. This does not mean accepting life and going into resignation. Nor being overly idealistic and only creating options without doing what is in front of us to do.

You could have filled your email with cries of, "Why me?" You didn't. You showed up in each situation and met life, caring for the people God put in your path. Without getting too heady, this is walking the path of social justice. We have to identify that there are needs for change, for changes in our systems (ex: what can we do for these young 20-something rangers who have life and death decisions to make), we have to work for change, and we have to not be attached to outcome. Without being attached to outcome we still need to work for justice. "Pray for the dead and fight like hell for the living." -Mother Jones A key component of resilience is acceptance of reality, life on life's terms. Not resignation. I have been amazed and grateful over and over again for the kind of resilience you demonstrate, and the resilience that is demonstrated by your staff as you make clear in your stories. Resilience is not about being "in good shape". Events like you described in your email do not leave us "in good shape"...

\section{-Shana}

I had always thought of resilience as not letting them seeing you sweat or that things bothered you. I had not looked at it through the acceptance filter...that life is what it is. This is going to take much more reflection. Thank you for sharing this... $-\mathrm{J}$. 


\section{Ritualized Ingenuity}

The third building block of resilience is the ability to make do with whatever is available within the parameters of established practices. There are two sides to this. On the one hand, making do with what is available and being very good at improvisation. On the other hand, rules and structures. This is the paradox of ingenuity. When individuals and organizations have a strong foundation and know their parameters, including strengths and shadows, they are better able to be resourceful.

The following is a story about ingenuity and going beyond the perceived boundaries to access resources, to get more than what appeared to be available.

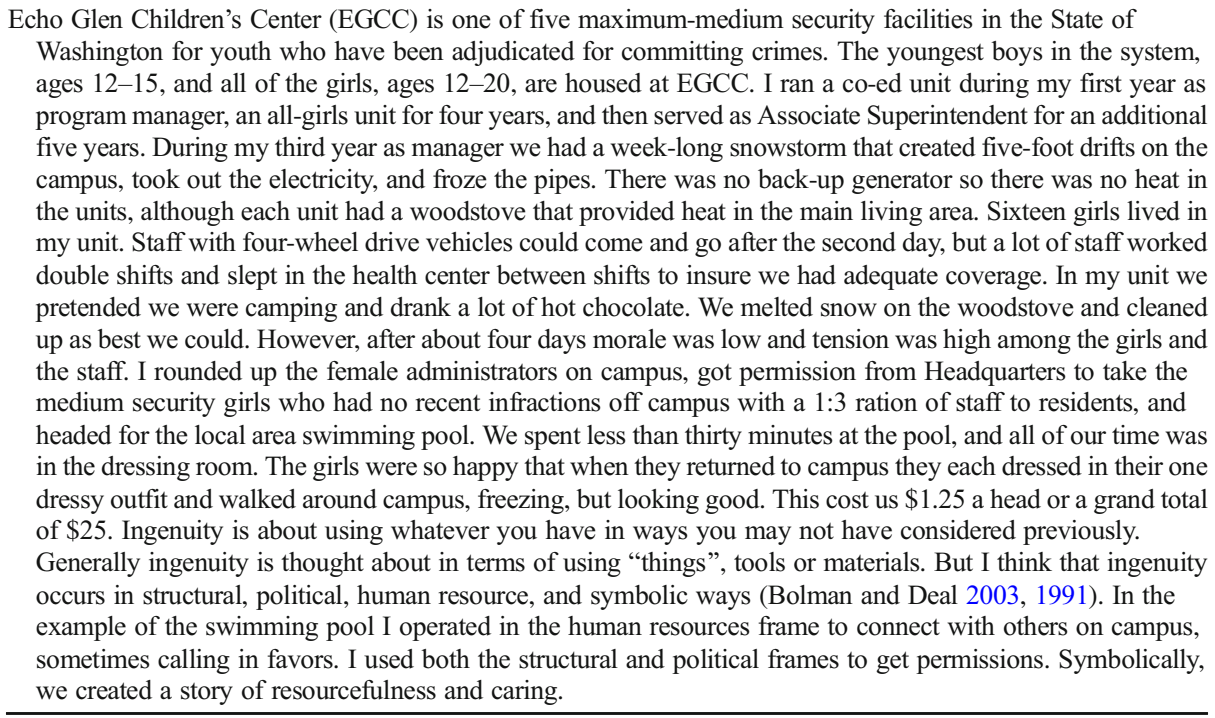

Sometimes ingenuity looks like an intricate, beautiful weaving or an amazing idea that appeared out of the clear blue sky, but more often it looks like the messy kitchen drawer that contains a bit of everything. Who knows what will be needed or when, but a bit of everything is available. Older and more mature systems have experienced hard times and developed coping strategies. They have several kitchen drawers full of policies, procedures, and improvisations; they have created options. A young person or young organization has little history, so when tragedy happens the system must develop responses, learn to adapt. Ingenuity grows as individuals and organizations gain experiences. The challenge is to learn from those experiences (Maddi 2002).

\section{The Shadow of Resilience}

Viktor Frankl, a writer, teacher, and concentration camp survivor wrote that the best people did not survive the concentration camps. He believed that they were not willing to take resilience to the extreme, to do whatever they needed to do to survive: 
On the average, only those prisoners could keep alive who, after years of trekking from camp to camp, had lost all scruples in their fight for existence; they were prepared to use every means, honest and otherwise, even brutal... in order to save themselves. We who have come back...we know: The best of us did not return (Frankl quoted in (Maddi 2002)).

"The best of us did not return" is a haunting thought. All three characteristics of resilience are held in this quote:

- Facing down reality: The concentration camp prisoners faced reality, stark reality, on a daily basis. These days stretched to years. Life events were filled with terror. Those who were overly optimistic often became bitter or gave up. Survivors struggle today, years later, to talk about the unspeakable.

- Search for meaning: Control over their environment was reduced to next to nothing. Therefore, they could not rely on external control to make meaning; in these conditions the temptation is strong to fall into hopelessness and helplessness, to fail to thrive. Some found meaning in resistance, some in helping others, some in basic, even brutal, survival.

- Ritualized ingenuity: Ingenuity and learning from one's experiences occurred in concrete, very specific ways; for example, how to treat certain guards, or the strategy of guarding pieces of string that could come in handy for trade at a later date. The ability to learn from one's experiences was critical for survival in the camps.

I asked a colleague to read and comment on this paper. She wrote this about Viktor Frankl's quote:

Whoa. This definitely triggers something for me as a Jew. Personally, this idea, that all survivors were brutal and unscrupulous, is very hard for me to swallow. Is this perhaps about Frankl's own survivor guilt? Does extreme resilience HAVE to mean extreme loss of humanity? Could there have been extreme acts of cooperation? I don't know. The connotation, if the best did not survive, is that the worst, the degenerate (hmm, sounds like perpetrators' words) did survive-and engendered the parents of many Jews living today. So presentday Jews are a reduced race. Hmm, again, those sound like the words of the perpetrators. Ethnicity, trauma, and self-hatred are wound together very intricately! (Blythe Horman, personal correspondence, June 10, 2005)

Frankl's words, "The best of us did not return" are harsh and seem to allow no room for forgiveness - of self or others. Some of this harshness may well come from guilt, even shame, at being a survivor. Unfortunately, 'survivor guilt' is a common experience in survivors of war (Herman 1992).

Frankl surfaces the Shadow associated with the Strength of resilience, the brutality that may be necessary for survival. Viewed in this way, trauma and resilience look very similar. Results from early studies on resilience conducted by Haggerty et al. (Haggerty et al. 1994), the studies of children who grew up with mentally ill parents, 
indicate that the children built ongoing connections to others, were vigilant, and were astute about their environments. These abilities allowed them to be resilient. However, later studies with high-risk youth indicate that the Strengths from childhood can become Shadows by adolescence. Ongoing connections to others can develop into poor boundaries or unhealthy dependence. Need for connection may trap individuals in unhealthy, harmful, or brutal relationships as the victim or the perpetrator. Vigilance can become hypervigilance. Astuteness at reading the environment can become high anxiety or depression (Luthar 1991). The cost of resilience can be high.

\section{Hope}

Facing down reality, making meaning, and ritualized ingenuity are gifts individuals and organizations give themselves and one another. They are gifts of hope. In times of despair, hope is essential. Hope is the fuel that helps individuals, organizations and communities to invest and rebuild, reconnect with dreams and one another, and look to the future (Walsh 2007). Research indicates that empowering leadership and unrelenting optimism are significantly related to building and sustaining resilience (Nguyen et al. 2016). While facing trauma and in its aftermath, leaders must model optimism and hope in the organization's mission and in future possibilities.

\section{Leadership}

When an organization identifies that it is traumatized and suffering, leaders must respond to address the trauma and to build and strengthen resilience, resilience that is beyond self-righting, resilience that supports well-being flourishing for the organization. Demonstrations of health include positive adaptation, ability to obtain and use resources, and improved employee engagement and performance (Kuntz et al. 2016).

Leaders need to provide forums for members to identify, recognize, honor, and learn from one another within their organizations. Additionally, members need opportunities to look around and see what is taking place in other organizations and communities. Learning from others and with others breaks the myth that any one person, team, or organization can and should have all the answers. One characteristic of resilience is not enough, at least two are needed and all three make for a solid foundation (Coutu 2002). Any one of the characteristics of resilience builds strength, two begin to build resilience, and all three are a foundation for health and hope.

When I was program manager of the girls' unit at Echo Glen Children's Center a white 'gangsta girl' entered the unit (her term). She assured us we were not going to change her. She presented as angry and hostile. Most of the girls spent hours listening to music on their headsets. This young woman spent hours drawing. During her two years of incarceration she completed her high school degree and was subsequently accepted on an art scholarship at a university. Together with my staff team I held hope, a vision, and the boundaries of a safe environment. She faced the reality that life in a gang is not a long one, found meaning in her art, and was innovative as well as creative to get resources she needed, art supplies and time. 
I recall a young Native Alaskan woman at the domestic violence shelter in Juneau, Alaska. She had two small children with her, ages 4 and 2. When I looked in that young mother's eyes, I saw a drowning woman. She was beaten, physically, emotionally, and spiritually, and felt helpless and hopeless. She could not imagine her life other than being terrorized at home or living with strangers in a shelter. While we were sitting together in the living room I picked up a book and said, "Who would like to hear a story?" With a child snuggled up on each of us we sat and read together for an hour. For that time she was safe and light shone from her eyes. Her choices did not change and she still had difficult decisions to make. But she reconnected to purpose and hope for herself and her children; life had meaning once again.

I am not Pollyannaish about domestic violence. Breaking the cycle of abuse, especially when that cycle is intergenerational, is extremely difficult. Having hope and making meaning in one moment does not mean that we automatically hold onto them, does not mean that this young woman will always have them. But this young woman came to know that she valued safety for her children. Once we know something deeply we cannot not know.

I choose life. I choose a definition of resilience that begins from an appreciative place of healing and wellness and moves out to include a firm grasp of reality, search for meaning, and ritualized ingenuity. Resilience must begin with an intention. My intention is to support wellness in individuals and organizations, to lift up hope. Each time we build hope we commit an act of resilience.

\section{Appendix 1}

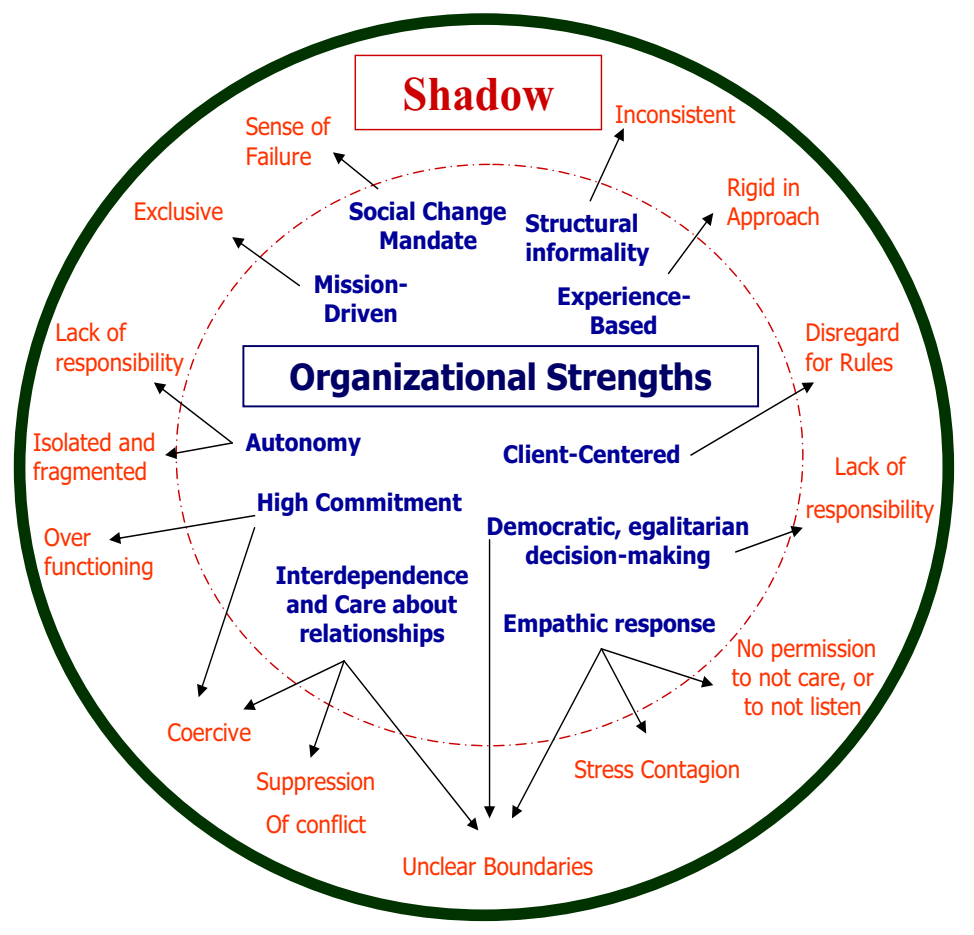

Copyright Shana Hormann, MSW and Pat Vivian, MA May 2002

Fig. 1 Strengths and shadows model 


\section{Appendix 2}

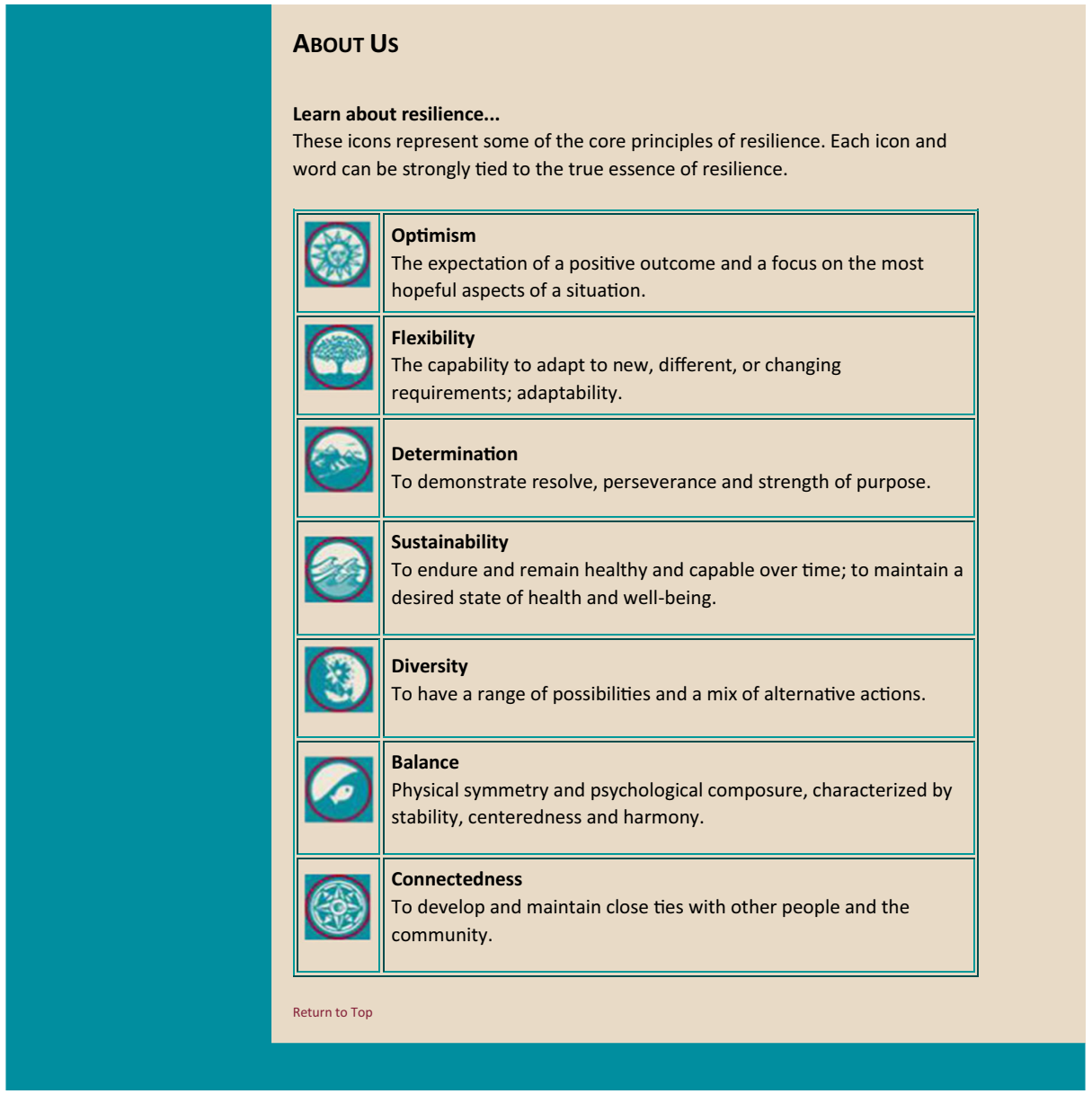

Fig. 2 A Model for learning about resilience: arizona State University resilience solutions group

\section{Appendix 3}

\section{Personal Reflection}

Conversations, readings, and months of internal processing with a focus on resilience formed a journey to my center, to what has meaning, to how I create and nurture hope. I walked a muchtraveled path, and am grateful for those in whose footsteps I tread. Geoff Bellman, my mentor faculty, and I had many conversations about trauma and resilience, and the importance of reflection. Geoff provided feedback all along the way. I have benefited greatly from his mentorship:

1 Example of giving feedback on interactions 
During one session Geoff commented that I was nodding my head at almost every statement he made. He described this as "overly affirming" and unnecessary. He paused and then said that he didn't like the behavior, and that was his bias, and that the behavior is probably very useful in group settings when I am facilitating (a common activity for me as an instructor). I appreciated both the feedback about my behavior and his transparency about his bias. I also appreciated that he considered the strength of the behavior, and in what contexts the behavior would be an asset. His modeling informed my advising with students.

\section{Example of giving feedback on the writing process}

Probably the short form is to say that my writing process drove Geoff crazy. But the more accurate statement is a bit longer. At one point Geoff asked me for an image of myself. The word that came to me was "churning". He gave me the feedback that he could see that I was "churning" and recommended that I stop. "Churning" behaviors included research, reading, mulling, stewing... The shadow that he helped to highlight is my perfectionism. I wanted to "know" everything already written about resilience before committing myself on paper. He encouraged me to contribute, to share my perspective and experience. Based on our conversations he had confidence that I knew about resilience and could write on the subject. But I could not write. Or, more accurately, I could not write anything that made me feel satisfied. What I discovered about my learning process is that I am confident that I know material when I can apply it, when I can teach it to others. After presenting information on resilience to students and assisting them with identifying resilience in their organizations, I now "own" resilience. I do not know all there is to know about the topic, but today I have a relationship with resilience. Evidently I build rapport quickly but take a long time to build relationships.

\section{Example of giving feedback on self-awareness}

Geoff emphasized reflection. He pointed out that in good times we need to pause and reflect, to anchor our positive experiences so their gifts will strengthen us in hard times. He shared personal and professional examples and what he learned from them. His modeling gave me courage/encouraged me to share my own examples and look deeply at what I learned.

\section{References}

Alper, J. 1992. Everglades Rebound From Andrew. Science. 257 (5078): 1852-1854.

Bell, H. 2003. Strengths and secondary trauma in family violence work. Social Work 48 (4): 513-522.

Bellman, G.M., and K.D. Ryan. 2009. Extraordinary groups: How ordinary teams achieve extraordinary results. San Francisco: Jossey-Bass.

Bolman, L.G., and T.E. Deal. 1991. Leadership and management effectiveness: A multi-frame, multi-sector analysis. Human Resource Management. 30 (4): 509.

Bolman, L.G., and T.E. Deal. 2003. Reframing organizations: Artistry, choice, and leadership. San Francisco: Jossey-Bass.

Bride, B.E., M. Radey, and C.R. Figley. 2007. Measuring compassion fatigue. In Clinical social work journal (35)3, 155-163.

Cicchetti, D., F. Rogosch, et al. 1993. Resilience in maltreated children: Processes leading to adaptive outcome. Development and Psychopathology 5: 629-647.

Coutu, D. 2002. How resilience works. Harvard Business Review 80 (5): 46-52.

Figley, C.R., ed. 1995. Compassion fatigue: Coping with secondary traumatic stress disorder in those who treat the traumatized. Florence: Brunner/Mazel. 
Haggerty, R., N. Garmezy, et al., eds. 1994. Stress, risk, and resilience in childhood and adolescence. New York: Cambridge University Press.

Hammond, S.A., and A.B. Mayfield. 2004. The thin book of naming elephants: How to surface undiscussables for greater organizational success. Bend: OR, Thin Book Publishing Co.

Herman, J. 1992. Trauma and recovery. New York: Basic Books.

Hormann, S., and P. Vivian. 2004. Seattle rape relief: Organizational trauma, agency closure, and interventions that might have made a difference. In Unpublished manuscript.

Hormann, S., and P. Vivian. 2005. Intervening in traumatized organizations. Traumatology, The International Journal 11 (3): 159-169.

Horne, J.F., and J.E. Orr. 1998. Assessing behaviors that create resilient organizations. Employment Relations Today Winter: 29-39.

Kuntz, J.R.C., K. Naswall, and S. Malinen. 2016. Resilient employees in resilient organizations: Flourishing beyond adversity. Industrial and Organizational Psychology 9 (2): 456-462.

Luthans, F. and Avolio, B. 2003 "Authentic Leadership Development" Chapter 16 in Cameron, K., Dutton, J.E., and Quinn R.E. Positive Organizational Scholarship. San Francisco, Berrett-Koehler Publishers, Inc., 241258 .

Luthar, S.S. 1991. Vulnerability and resilience: A study of high-risk adolescents. Child Development 62: 600616.

Luthar, S.S., D. Cicchetti, et al. 2000. Research on resilience: Response to commentaries. Child Development 71 (3): $573-575$.

Maddi, S.R. 2002. The story of hardiness: Twenty years of theorizing, research,a nd practice. Consulting Psychology Journal: Practice and Research 54 (3): 175-185.

Masten, A.S., and J.D. Coatsworth. 1998. The development of competence in favorable and unfavorable environments: Lessons from research on successful children. American Psychologist 53 (2): 205-220.

Nguyen, Q., J.R.C. Kuntz, K. Naswall, and S. Malinen. 2016. Employee resilience and leadership styles: The moderating role of proactive personality and optimism. New Zealand Journal of Psychology 45 (2): 13-21.

Okey, T. 2000. Exxon Valdez Oil Spill. E-Magazine(May-June): 34-38.

Palmer, Parker J. Noetic Sciences Review. Winter. 96 (40): 32-41.

Riolli, L., and V. Savicki. 2003. Information system organizational resilience. Omega 31 (3): 227-233.

Schaef, A.W., and D. Fassel. 1988. The addictive organization. San Francisco: Harper \& Row.

Seligman, M.E.P., and M. Csikszentmihalyi. 2000. Positive psychology. American Psychologist 56: $216-217$.

Senge, P. 1999. The dance of change: The challenges to sustaining momentum in learning organizations. New York: Doubleday.

Stamm, B.H., ed. 1999. Secondary traumatic stress: Self-care issues for clinicians, researchers, and educators. Baltimore: Sidran Press.

Steinmetz, S., J.L. Dowling, et al., eds. 1998. Random House Webster's College Dictionary. New York: Random House.

Sutcliffe, K.M. and Vogus, T.J. 2003 "Organizing for Resilience" Chapter 17 in Cameron, K., Dutton, J.E. and Quinn, R.E. Positive Organizational Scholarship. San Francisco, Berrett-Koehler Publishers, Inc., 94-110.

Violanti, J.M., and A. Gehrke. 2004. Police trauma encounters: Precursors of compassion fatigue. International Journal of Emergency Mental Health 6 (2): 75-80.

Vivian, P., and S. Hormann. 2002. Trauma and healing in organizations. O.D. Practitioner 34 (4): 52-57.

Walsh, F. 2007. "Traumatic loss and major disasters: Strengthening family and community resilience.".

Werner, E.E. 1995. Resilience in development. American psychological Society: 81-85.

Wolin, S. and S. Wolin 1994. People at Promise, SAMHSA: National Mental Health Resource Center. 